\title{
A Low-Profile Broadband Array Antenna for Home Repeater Applications
}

\author{
Sung Joon Yoon· Jaehoon Choi*
}

\begin{abstract}
This paper reports on the proposed design of a low profile broadband array antenna for home repeater applications. The proposed antenna consists of $1 \times 4$ patch elements and two ground planes, one of which is slitted. By using the gap feeding method, the impedance matching of the antenna is improved by a multi-resonance phenomenon. The proposed antenna provides a wide $-10 \mathrm{~dB}$ reflection coefficient bandwidth simultaneously covering the Global System for Mobile communications (GSM-1800), Personal Communications Service (PCS), and the Universal Mobile Telecommunication System (UMTS) bands (1.67-2.32 GHz). In order to reduce the mutual coupling between adjacent patch elements, slits are embedded in the ground plane. An isolation level of $-20 \mathrm{~dB}$ is realized over the entire operating frequency band.
\end{abstract}

Key Words: Gap Feeding, Repeater Antenna, Slitted Ground.

\section{INTRODUCTION}

Mobile and wireless communication technologies have developed rapidly in order to satisfy the growing demands for highcapacity and high-speed data transmission. The transmission of a high quality signal to a receiver within telecommunication systems requires base stations that generate cell coverage. The coverage area is defined as the total area within the reach of the signal. However, in cities with many obstacles, communication quality can be degraded at cell edges. Such obstacles include shadowed areas, tunnels, and buildings. To improve the communication quality and to extend the coverage area with effective cost, a repeater system is necessary in modern communication systems [1].

Microstrip patch antennas are commonly used in repeater applications because of low production cost, easy fabrication, light weight, and their low profile. However, a typical mi- crostrip patch antenna has a narrow bandwidth. Thus, several methods have been introduced to widen the bandwidth using different types of feed structure [2-6]. Commonly used feeding methods to enhance the bandwidth include: the coplanar waveguide-fed (CPW) technique [2], a U-shaped feed [3, 4], a probe feed with a $\mathrm{W}$-shaped ground [5], and an L-probe feed [6], which enhance the bandwidth by up to $25 \%$. However, these antennas cannot cover Global System for Mobile Communications (GSM-1800), Personal Communications Service (PCS), and the Universal Mobile Telecommunication System (UMTS) [7] frequency bands, simultaneously.

To overcome this problem, we propose a low-profile broadband $1 \times 4$ array antenna for home repeater applications. The proposed antenna uses the gap feeding between the patch elements and feeding strip to achieve the wide bandwidth characteristic [8]. In order to decrease the mutual coupling without increasing the physical separation between patch elements, slits

Manuscript received May 25, 2018 ; Accepted August 6, 2018 ; Accepted September 12, 2018. (ID No. 20180525-045J)

Department of Electronics and Computer Engineering, Hanyang University, Seoul, Korea.

"Corresponding Author: Jaehoon Choi (e-mail: choijh@hanyang.ac.kr)

This is an Open-Access article distributed under the terms of the Creative Commons Attribution Non-Commercial License (http://creativecommons.org/licenses/by-nc/4.0) which permits unrestricted non-commercial use, distribution, and reproduction in any medium, provided the original work is properly cited.

(c) Copyright The Korean Institute of Electromagnetic Engineering and Science. All Rights Reserved. 
are added to ground plane 1 [9]. The antenna has a wide bandwidth (1.67-2.32 GHz) covering the GSM-1800 (1.71-1.88 $\mathrm{GHz})$, PCS (1.85-1.99 GHz), and UMTS (1.92-2.17 GHz) frequency bands. FR-4 substrate 2 with ground plane 2 (GND2) is located under the bottom of substrate 1 as a reflector, which makes the radiation pattern unidirectional with a high gain level over the operating frequency band.

\section{ANTENNA DESIGN}

Fig. 1 shows the geometry of the proposed antenna. The proposed antenna was designed on an FR-4 substrate $\left(\varepsilon_{r}=4.4\right.$, $\tan \delta=0.02), 1 \times 4$ array antenna with a separation distance between the adjacent elements of $110 \mathrm{~mm}$. Each antenna element is excited by a feeding strip located on the upper side of the FR-4 substrate 1. A multi-resonance characteristic was achieved by using the gap feeding between the patch element and feeding strip [8]. The ground plane 1 , with dimension of $85.7 \mathrm{~mm} \times 430 \mathrm{~mm}$, is located on the bottom side of the FR-4 substrate 1 . To improve the isolation characteristics between the antenna elements, slits were added to ground plane 1 . As shown in Fig. 1(a), the optimal length $l_{1}$ of the patch element, and the gap $g$ between the patch element and feeding strip, are $46 \mathrm{~mm}$ and $0.3 \mathrm{~mm}$, respectively. The dimensions of the Fr-4 substrate

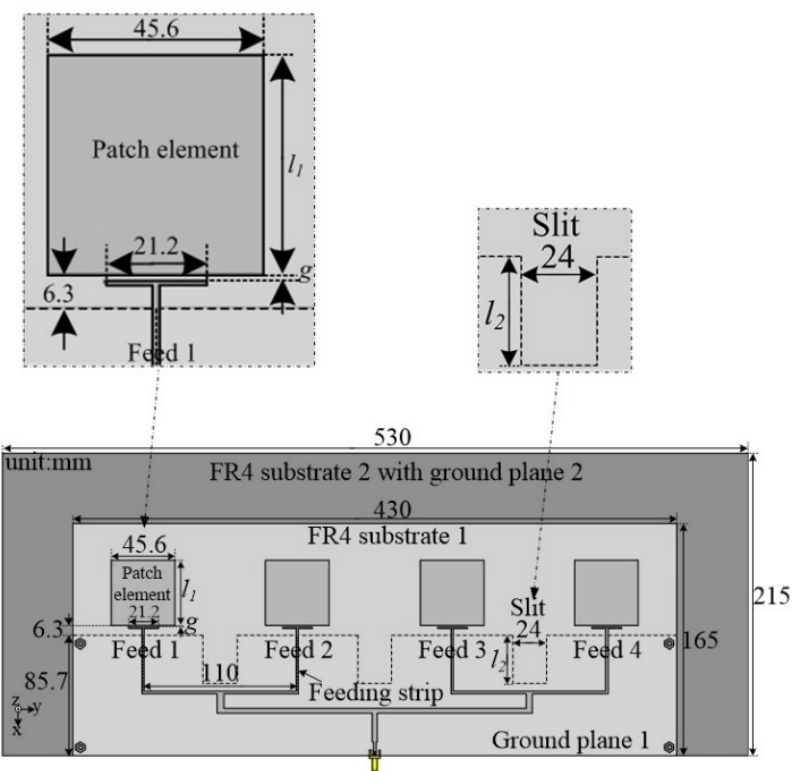

(a)

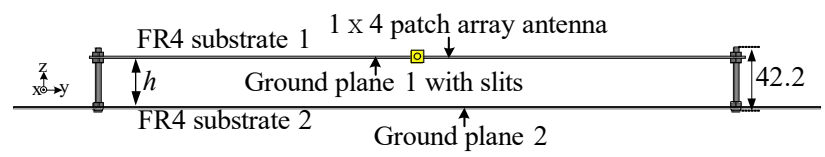

(b)

Fig. 1. Geometry of the proposed antenna: (a) top view, (b) side view.
1 and 2 are, respectively, $430 \mathrm{~mm} \times 165 \mathrm{~mm}$ and $530 \mathrm{~mm} \times$ $215 \mathrm{~mm}$ with a thickness of $0.8 \mathrm{~mm}$. To improve the gain and front-to-back ratio (FBR) of the proposed antenna, substrate 2 is placed $32.4 \mathrm{~mm}$ away from the bottom of substrate 1 . Metal bolts and nuts were used to fix substrate 1 and 2 with a height of $42.4 \mathrm{~mm}$.

\section{SIMULATED RESULTS AND ANALYSIS}

In order to analyze the effect of the gap feeding, the reflection coefficients of the proposed antenna and direct-fed antenna were compared, and the results are shown in Fig. 2. The directfed antenna has the same basic structure as the proposed antenna with the exception of feeding structure. By using gap feeding, impedance matching is improved and the $-10 \mathrm{~dB}$ reflection coefficient bandwidth simultaneously covers the GSM-1800 $(1.71-1.88 \mathrm{GHz})$, PCS $(1.85-1.99 \mathrm{GHz})$ and UMTS $(1.92-$ $2.17 \mathrm{GHz}$ ) bands. Simulation results were analyzed using an ANSYS High-Frequency Structure Simulator (HFSS) version 17.2 (ANSYS Inc., Canonsburg, PA, USA). Fig. 3 shows the simulated reflection coefficients when the gap $g$ between the patch element and feeding strip changed from $0.1 \mathrm{~mm}$ to 1.1 $\mathrm{mm}$. It showed that as $g$ decreases, the bandwidth of the antenna increases. This is especially important for PCS and UMTS bands that are critically affected by $g$. When $g$ was equal to 0.3 $\mathrm{mm}$, the antenna had a wider $-10 \mathrm{~dB}$ reflection coefficient bandwidth than that observed for gaps of $0.7 \mathrm{~mm}$ or $1.1 \mathrm{~mm}$. As the change in reflection coefficient bandwidth is negligible when the value of $g$ is less than $0.3 \mathrm{~mm}$ (i.e., $0.1 \mathrm{~mm}$ ), $0.3 \mathrm{~mm}$ is the optimized value of $g$ for easy fabrication. Fig. 4 illustrates the simulated reflection coefficients for various values of length $l_{1}$. A change in the $l_{1}$ value affects the resonance frequency and reflection coefficient. As $l_{1}$ decreased, the entire frequency band was shifted to the higher frequency side, whereas when the val-

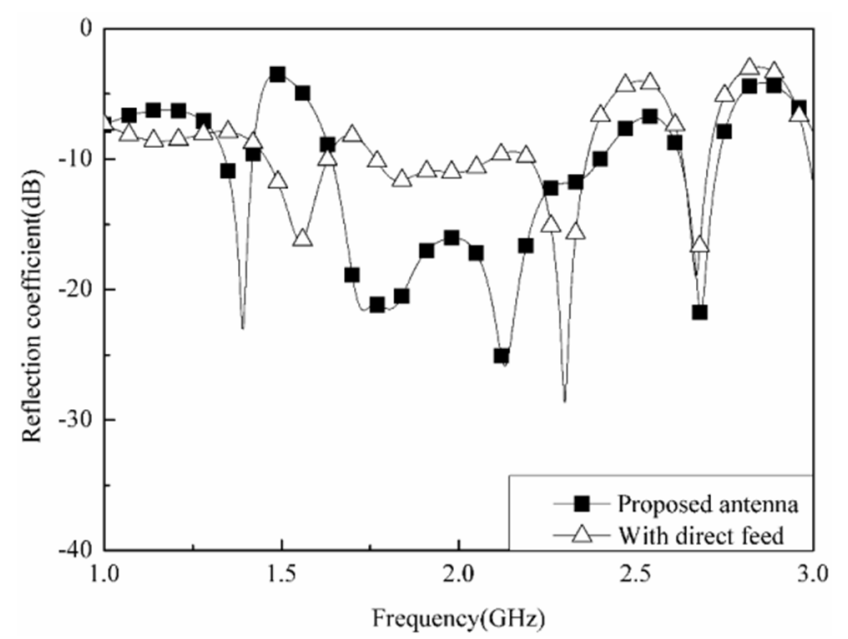

Fig. 2. Simulated reflection coefficients of the proposed antenna and the antenna with direct feed. 


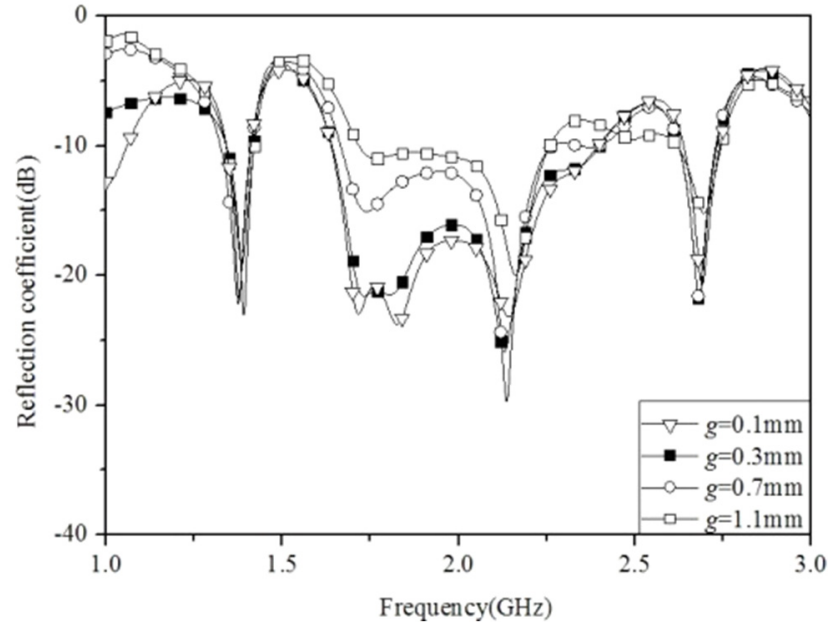

Fig. 3. Simulated reflection coefficients for various values of gap $g$.

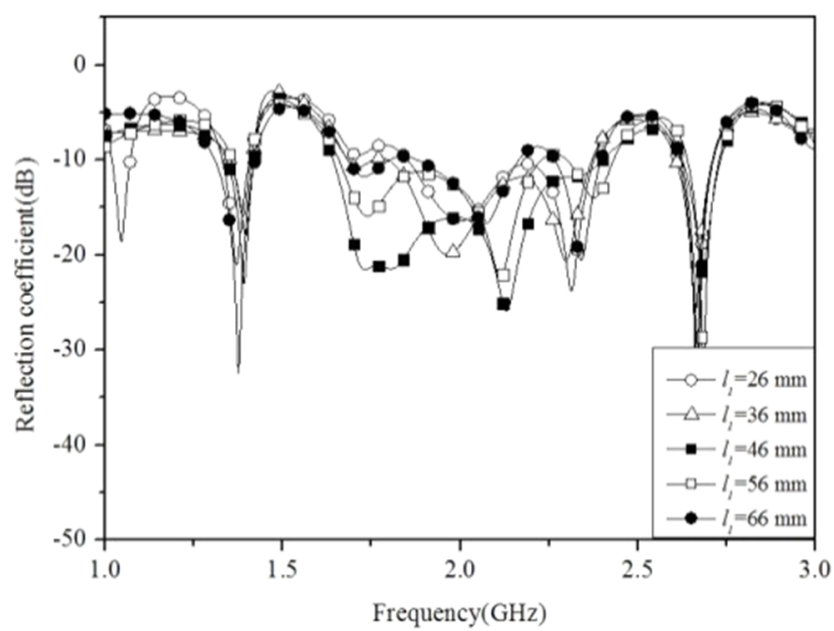

Fig. 4. Simulated reflection coefficients for various values of length $l_{1}$.

ue of $l_{1}$ increased, the resonance frequency was shifted to the lower frequency side. Optimum performance was achieved when $l_{1}$ was equal to $46 \mathrm{~mm}$.

In order to analyze the operational characteristics of the proposed antenna, the simulated electric field distributions on the antenna were analyzed as shown in Fig. 5. In Fig. 5(a), the proposed antenna is operating at $1.755 \mathrm{GHz}$ because each patch element has an effective electrical length of $\lambda / 2$. Fig. 5(b) and (c) show that the antenna operates at $1.97 \mathrm{GHz}$ and $2.16 \mathrm{GHz}$ because of the coupling between the patch elements and the ground plane.

In general, it is required that be sufficient space between patch elements in order to obtain a high isolation level [10]. However, a physical space that is too large can affect radiation performance, resulting in an increase of the side-lobe level and a decrease in peak gain $[11,12]$. By adding slits in the ground plane, the physical size of the antenna can be reduced and the mutual coupling between antenna elements decreases. The transmission coefficients of the proposed antenna with and without slits are compared in Fig. 6. Both antennas have the

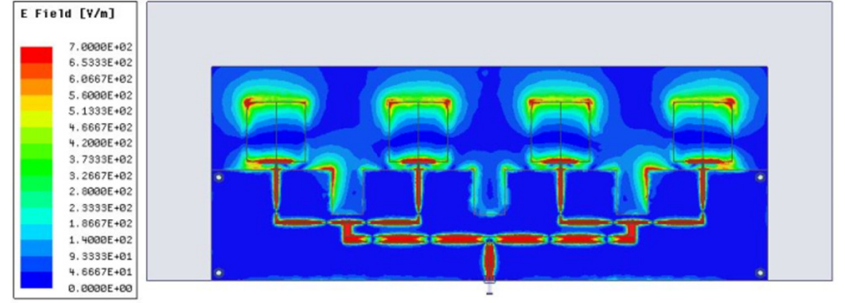

(a)

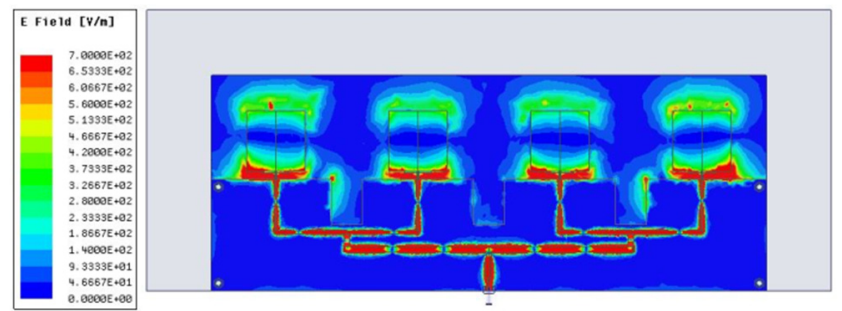

(b)

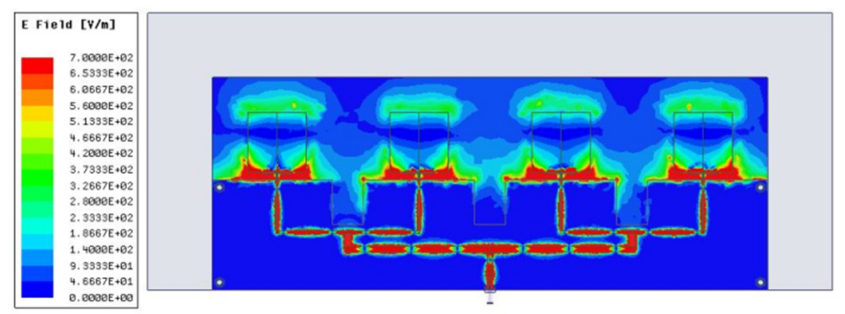

(c)

Fig. 5. Simulated electric field distributions of the proposed antenna at $1.755 \mathrm{GHz}(\mathrm{a}), 1.97 \mathrm{GHz}(\mathrm{b})$, and $2.16 \mathrm{GHz}$ (c).

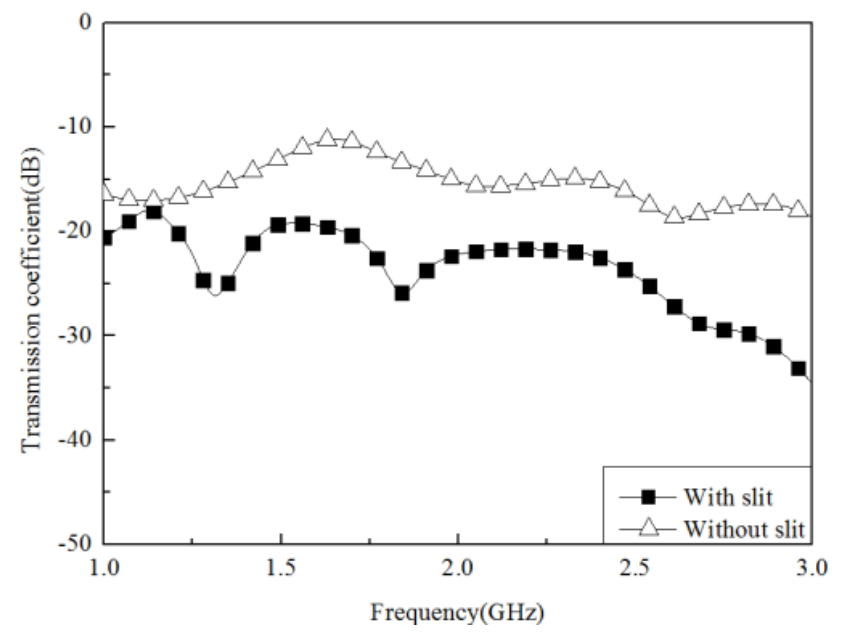

Fig. 6. Simulated transmission coefficients of the proposed antenna with and without slits.

same structure, the only difference between them being the presence or absence of slits.

The isolation level of $-20 \mathrm{~dB}$ is realized over the entire operating frequency band.

Fig. 7 shows the simulated transmission coefficient characteristics of the proposed antenna for various values of length $l_{2}$. It can be seen that as the length of $l_{2}$ increases, the isolation characteristic is improved. However, when $l_{2}$ is larger than the optimized values of $34.7 \mathrm{~mm}$, the mutual coupling increases in the 


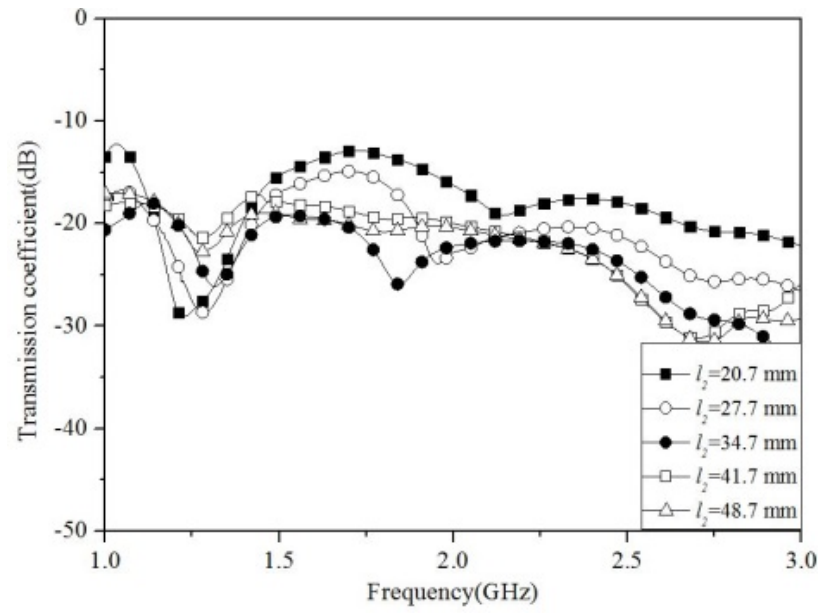

Fig. 7. Simulated transmission coefficients for various values of length $l_{2}$.

frequency range from $1.7 \mathrm{GHz}$ to $2.17 \mathrm{GHz}$. An optimal result is achieved when the length of $l_{2}$ is set to $34.7 \mathrm{~mm}$.

In order to improve the gain and FBR, substrate 2 with ground 2 is located at $0.28 \lambda$ from the FR-4 substrate 1 that act as a reflector. The length of $h$ is set at about a quarterwavelength of the center frequency, so that the reflected wave from the reflector is in phase with the forward wave excited by the array antenna [11].

The yz plane radiation patterns for various values of $b$ were simulated and are shown in Fig. 8. The best performance of the peak gain and FBR was obtained when $b$ was $32.4 \mathrm{~mm}$. At 2.16 $\mathrm{GHz}$, the maximum gain and FBR is superior to that of 1.755 $\mathrm{GHz}$ and $1.96 \mathrm{GHz}$, because the optimum distance of 34.7 $\mathrm{mm}$ is a quarter-wavelength of $2.16 \mathrm{GHz}$. As the value of $h$ increases to $44.4 \mathrm{~mm}$, the back lobe becomes larger. The peak gains are $10.14 \mathrm{dBi}(\mathrm{FBR}=11.09 \mathrm{~dB}), 10.58 \mathrm{dBi}(\mathrm{FBR}=14.81$ $\mathrm{dB})$, and $11.69 \mathrm{dBi}(\mathrm{FBR}=27.23 \mathrm{~dB})$ at $1.755 \mathrm{GHz}, 1.96 \mathrm{GHz}$, and $2.16 \mathrm{GHz}$, respectively.

\section{MEASURED RESULTS}

The comparisons of the peak gains and FBRs between the proposed antenna and the antenna without GND2 are shown in Table 1. The enhancement values of the peak gains and FBR are $5.57 \mathrm{~dB}(\mathrm{FBR}=10.63 \mathrm{~dB}), 6.6 \mathrm{~dB}(\mathrm{FBR}=14.99 \mathrm{~dB})$, and

Table 1. Peak gain and FBR comparisons between the proposed antenna and the antenna without GND2

\begin{tabular}{lccccc}
\hline \multirow{2}{*}{$\begin{array}{c}\text { Frequency } \\
(\mathrm{GHz})\end{array}$} & \multicolumn{2}{c}{ Peak gain $(\mathrm{dBi})$} & & \multicolumn{2}{c}{ FBR $(\mathrm{dB})$} \\
\cline { 2 - 3 } \cline { 5 - 6 } & $\begin{array}{c}\text { Proposed } \\
\text { antenna }\end{array}$ & $\begin{array}{c}\text { Without } \\
\text { GND2 }\end{array}$ & & $\begin{array}{c}\text { Proposed } \\
\text { antenna }\end{array}$ & $\begin{array}{c}\text { Without } \\
\text { GND2 }\end{array}$ \\
\hline 1.755 & 10.14 & 4.57 & & 11.09 & 0.46 \\
1.97 & 10.58 & 4.22 & & 14.81 & -0.18 \\
2.16 & 11.69 & 3.96 & & 27.23 & -0.22 \\
\hline
\end{tabular}

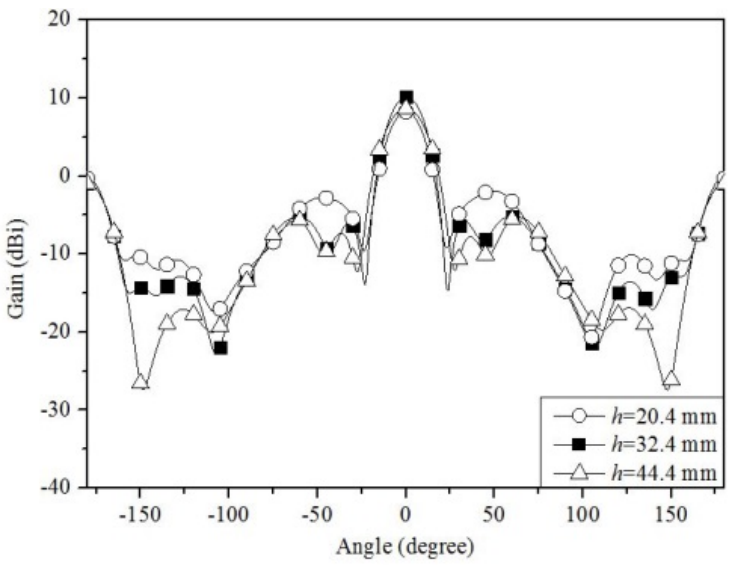

(a)

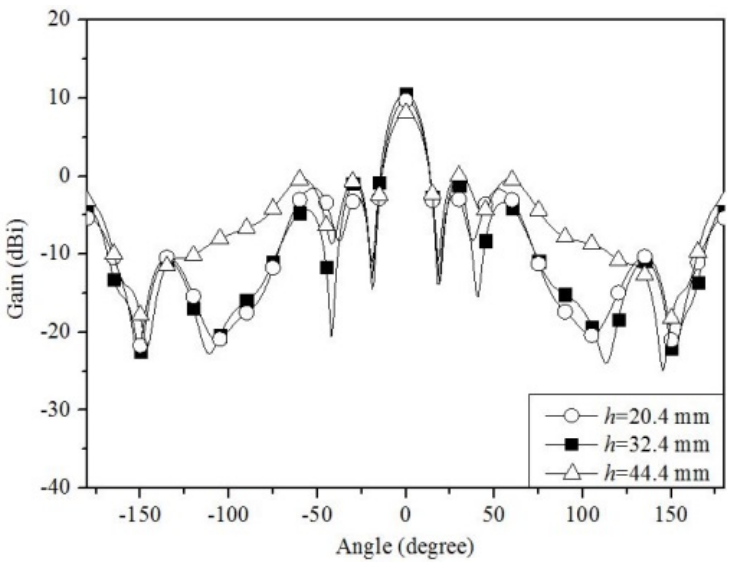

(b)

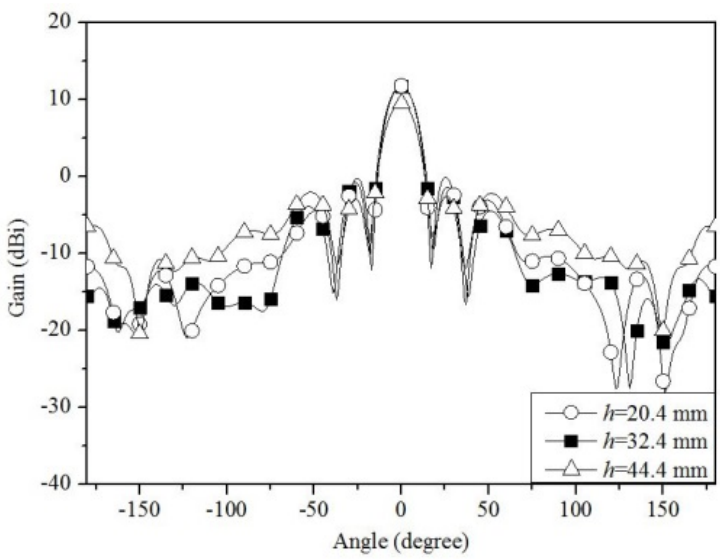

(c)

Fig. 8. Simulated yz plane radiation patterns of the antenna for various values of $h$ : (a) $1.755 \mathrm{GHz}$, (b) $1.97 \mathrm{GHz}$, and (c) $2.16 \mathrm{GHz}$.

$7.73 \mathrm{~dB}(\mathrm{FBR}=27.45 \mathrm{~dB})$ at $1.755 \mathrm{GHz}, 1.96 \mathrm{GHz}$, and 2.16 $\mathrm{GHz}$, respectively.

Fig. 9 shows a fabricated prototype of the proposed antenna. The simulated (with and without GND2) and measured reflection coefficients are compared in Fig. 10.

Both the simulated and measured results are in agreement with respect to the reflection coefficients. The measured $-10 \mathrm{~dB}$ reflection coefficient bandwidth $(1.67-2.32 \mathrm{GHz})$ is sufficient 


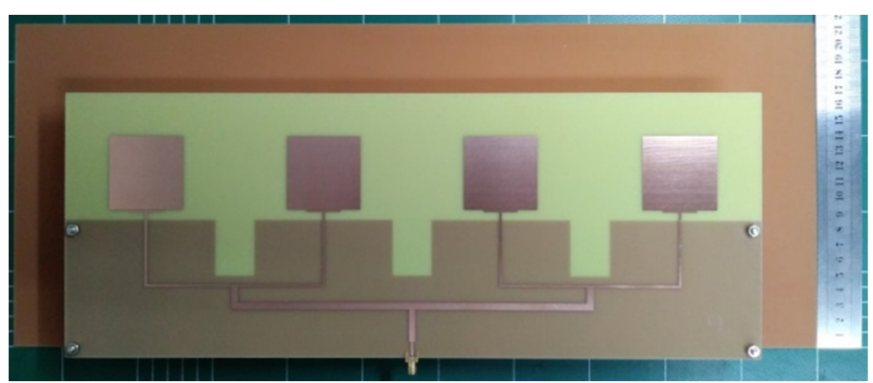

Fig. 9. Fabricated antenna.

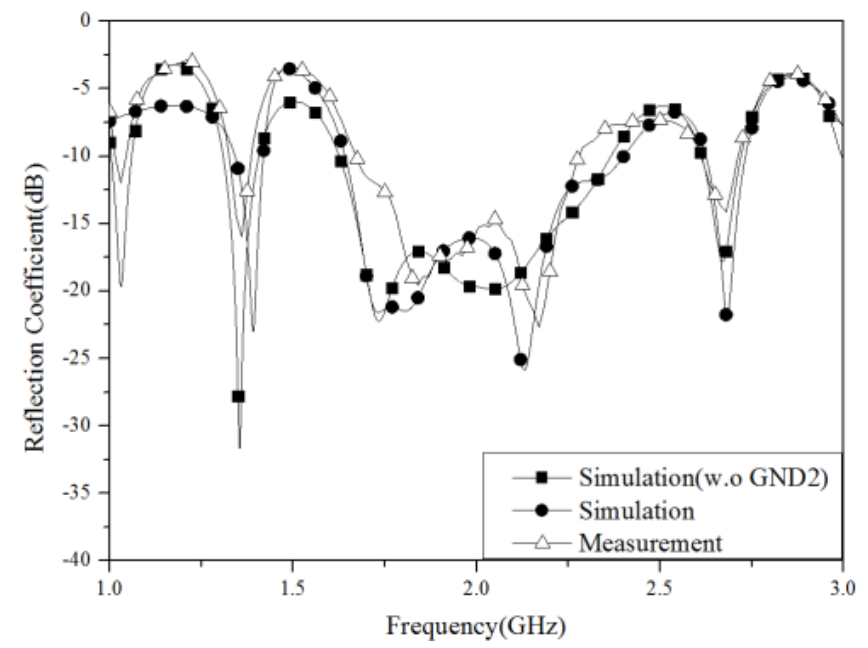

Fig. 10. Simulated (with and without GND2) and measured reflection coefficients of the proposed antenna.

to cover GSM-1800, PCS, and UMTS bands.

A comparison of the simulated (with and without GND2) and measured 2D radiation patterns of the proposed antenna are shown in Fig. 11. The simulated results are similar to the measurements. At the central frequencies of the operating bands $(1.755 \mathrm{GHz}, 1.97 \mathrm{GHz}$, and $2.16 \mathrm{GHz})$, the measured and simulated radiation pattern are almost identical. The measured peak gains of the proposed antenna are $9.21 \mathrm{dBi}, 9.61 \mathrm{dBi}$, and $9.12 \mathrm{dBi}$, respectively. The FBRs are $15.83 \mathrm{~dB}, 20.47 \mathrm{~dB}$ and $20.33 \mathrm{~dB}$, respectively.

\section{CONCLUSION}

In this paper, a low-profile broadband array antenna for home repeater applications is proposed. By using the coupling feed, the impedance matching of the proposed antenna is improved. Consequently, the proposed antenna has a wide $-10 \mathrm{~dB}$ reflection coefficient bandwidth of $650 \mathrm{MHz}(1.67-2.32 \mathrm{GHz})$ simultaneously covering GSM-1800, PCS and UMTS bands. The addition of slits in the ground plane decreases the mutual coupling with an isolation level lower than $-20 \mathrm{~dB}$ at the operating frequency band. The antenna has peak gains of $9.21 \mathrm{dBi}$, $9.61 \mathrm{dBi}$, and $9.12 \mathrm{dBi}$ with a unidirectional radiation pattern.

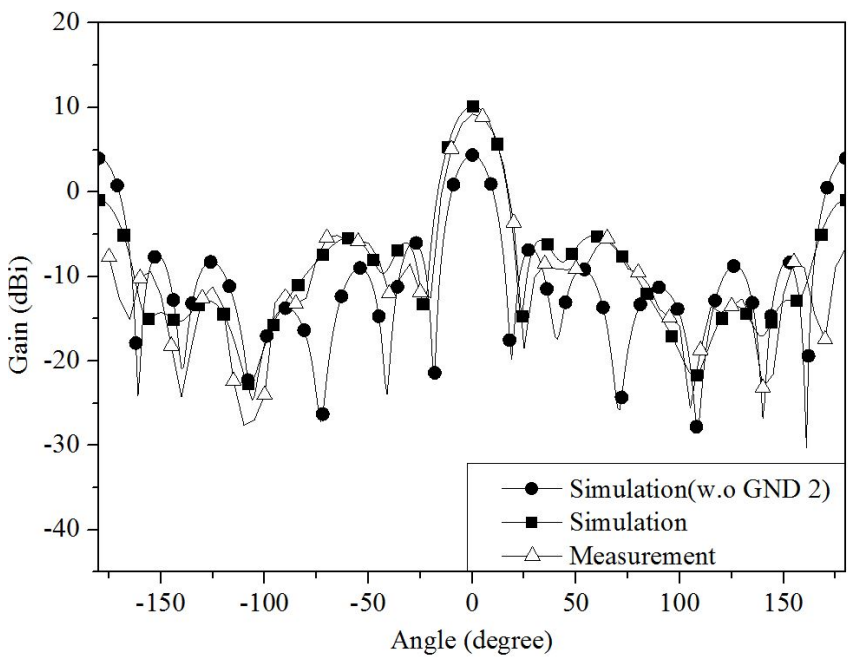

(a)

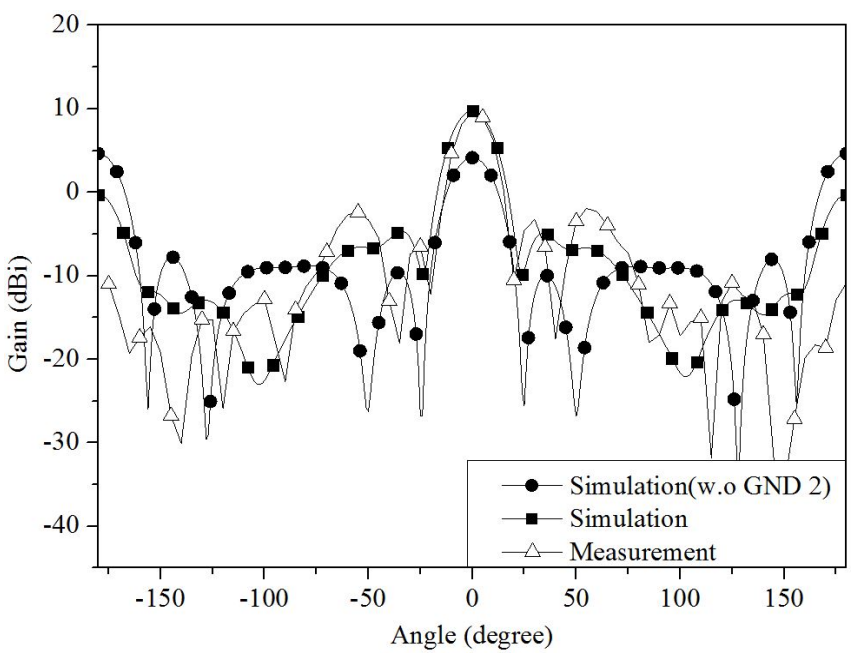

(b)

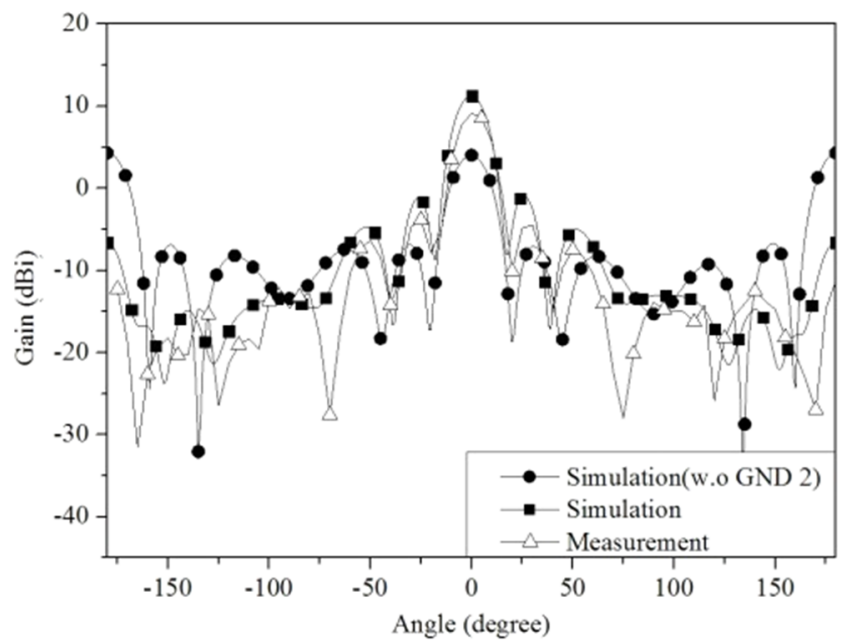

(c)

Fig. 11. Simulated (with and without GND2) and measured yz plane radiation patterns of the proposed antenna: (a) $1.755 \mathrm{GHz}$, (b) $1.97 \mathrm{GHz}$, and (c) $2.16 \mathrm{GHz}$.

Therefore, the antenna has the desired properties for repeater applications. 
This work was supported by a National Research Foundation of Korea (NRF) grant funded by Korea Government (MSIP) (No. 2017R1A2B4002811).

\section{REFERENCES}

[1] A. S. M. Marzuki, A. R. Rahim, B. Mohmd, K.Khalil, A. Naemat, and A. Tee, "Antenna isolation considerations in WCDMA repeater deployment," in Proceedings of 2006 International $R F$ and Microwave Conference, Putra Jaya, Malaysia, 2006, pp. 347-350.

[2] Z. Yang, X. Zhang, X. Teng, Z. Zhang, S. Li, and Y. Wang, "A novel low profile box-shaped antenna for a repeater system," in Proceedings of 2012 10th International Symposium on Antennas, Propagation \& EM Theory (ISAPE), Xian, China, 2012, pp. 93-96.

[3] T. Huynh and K. F. Lee, "Single-layer single-patch wideband microstrip antenna," Electronics Letters, vol. 31, no. 16, pp. 1310-1312, 1995.

[4] Z. Wang, S. Fang, S. Fu, and X. Li, "A wideband stacked plate antenna with a U-shaped ground plane for UHF CMMB repeater," in Proceedings of 2010 9th International Symposium on Antennas, Propagation and EM Theory (ISAPE), Guangzhou, China, 2010, pp. 71-74.

[5] K. L. Wong, C. L. Tang, and J. Y. Chiou, "Broadband probefed patch antenna with a W-shaped ground plane," IEEE Transactions on Antennas and Propagation, vol. 50, no. 6, pp 827-831, 2002.

\section{Sung Joon Yoon}

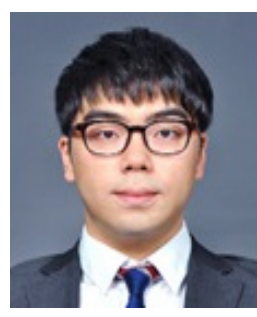

received his B.S. in electrical engineering from Chung-Ang University in Seoul, Korea, in 2015. He is currently working toward a combined Master's and Ph.D. degrees in the Department of Electronics and Computer Engineering at Hanyang University in Seoul, Korea. His research interest focuses on various antenna designs, mainly compact multi-band antennas for mobile wireless communication.
[6] J. S. Park, I. Kim, H. Kim, S. R. Lee, Y. S. Eo, and J. G. Kim, "Wideband microstrip conformal patch array antenna with tilted beam," The Journal of Korean Institute of Electromagnetic Engineering and Science, vol. 27, no. 5, pp. 416-423, 2016.

[7] M. K. Meshram, R. K. Animeh, A. T. Pimpale, and N. K. Nikolova, "A novel quad-band diversity antenna for LTE and Wi-Fi applications with high isolation," IEEE Transactions on Antennas and Propagation, vol. 60, no. 9, pp. 43604371, 2012.

[8] D. F. Guan, Y. S. Zhang, Z. P. Qian, Y. Li, W. Cao, and F. Yuan, "Compact microstrip patch array antenna with parasitically coupled feed," IEEE Transactions on Antennas and Propagation, vol. 64, no. 6, pp. 2531-2534, 2016.

[9] J. OuYang, F. Yang, and Z. M. Wang, "Reducing mutual coupling of closely spaced microstrip MIMO antennas for WLAN application," IEEE Antennas and Wireless Propagation Letters, vol. 10, pp. 310-313, 2011.

[10] K. R. Jha and S. K. Sharma, "Investigation on isolation of LTE 700/800 MHz band antennas for wireless repeater applications," in Proceedings of 2015 IEEE Applied Electromagnetics Conference (AEMC), Guwahati, India, 2015, pp. $1-2$.

[11] C. A. Balanis, Antenna Theory: Analysis and Design, 3rd ed. Hoboken, NJ: John Wiley \& Sons, 2005.

[12] D. S. Park, Y. K. Ko, and J. H. Choi, "A study on radiator of VHF-band active electronically scanned array with the trapezoidal dipole structure using meander-line," The Journal of Korean Institute of Electromagnetic Engineering and Science, vol. 27, no. 12, pp. 1027-1035, 2016.

Jaehoon Choi

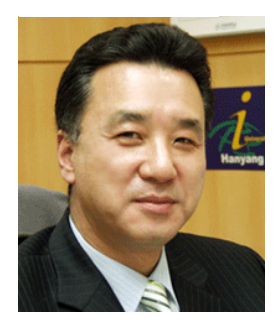

received his B.S. degree from Hanyang University, Korea, and M.S. and Ph.D. degrees from Ohio State University, Ohio, in 1980, 1986, and 1989, respectively. From 1989 to 1991 he was a research analyst at the Telecommunications Research Center at Arizona State University in Tempe, Arizona. He has also worked for Korea Telecom as a team leader of the Satellite Communication Division from 1991 to 1995. Since 1995, he has been a professor in the Department of Electronics and Computer Engineering at Hanyang University, Korea. He has published more than 290 refereed journal articles and numerous conference proceedings. He also holds over 90 patents. His research interests include antenna, microwave circuit design, and EMC. Currently, his research is mainly focused on the design of a compact multiband antenna for mobile wireless communication and antennas for biomedical applications. 